\title{
A STUDY OF ROLE OF IMMEDIATE TRACHEOSTOMY IN CRITICALLY ILL ADULT PATIENTS IN AN ICU OF TERTIARY HOSPITAL OF ANDHRA PRADESH
}

\author{
Yarlagadda Subba Rayudu1, N. Sateesh Chandra², Velchuri Venkata Krishna Sandeep ${ }^{3}$ \\ 1 Professor, Department of ENT, NRI Medical College, Guntur. \\ ${ }^{2}$ Associate Professor, Department of ENT, NRI Medical College, Guntur. \\ ${ }_{3}^{3}$ Assistant Professor, Department of ENT, NRI Medical College, Guntur.
}

\begin{abstract}
\section{BACKGROUND}

Tracheostomy is done in patients with compromised airway to simplify its long term effects on the outcome of the underlying disease. Indications of tracheostomy have not changed but its timing has been shown to have definite effect on the outcome of the underlying disease. In most of the ICU setups, immediate intubation tides over the crisis of airway obstruction and tracheostomy is done electively when the underlying disease seems to be far from recovery.

To compare the differences between immediate and elective tracheostomy irrespective of the underlying disease in terms of Ventilator Support Duration (VSD), ICU stay (ICUS), Total Hospital stay (THS), incidence of pulmonary complications (PC) and Final Hospital outcome (FHO).
\end{abstract}

\section{MATERIALS AND METHODS}

Patients are divided in to two groups. In group "A", 42 patients were performed immediate tracheostomy as soon as the airway obstruction is noticed. In group "B", 46 patients underwent tracheostomy electively 10 days after endotracheal intubation. Demographic data, acute pathophysiology, Glasgow Coma Scale (GCS) were noted. The VSD, ICUS, PC, FHO were calculated.

\section{RESULTS}

Patients of both groups were randomised to either immediate or elective tracheostomy. The demographic data was similar in both the groups. There was no significant difference between the two groups in regards with initial clinical and laboratory data to account statistically. The GCS was $5.2 \pm 1.86$ Vs. $5.8 \pm 2.3$, APACHE II score was $20.82 \pm 1.5$ Vs. 22.38 \pm 2.1 . Statistical significance between the two groups in relation to VSD, ICUS and PC was observed with a p value of 0.041 ( $p$ significant at 0.05 ).

\section{CONCLUSIONS}

The study supports immediate tracheostomy irrespective of the initial assessment of underlying disease and airway compromise as the parameters like Ventilator Support Duration, ICU Stay, Pulmonary Complications, Total Hospital Stay are shorter and statistically significant unlike the elective tracheostomy which is done after 10 or more than 10 days of endotracheal intubation.

\section{KEYWORDS}

ICU, Immediate Tracheostomy, Elective Tracheostomy, Air Way, Critically Ill, Ventilator, Criteria.

HOW TO CITE THIS ARTICLE: Rayudu YS, Chandra NS, Sandeep VVK. A study of role of immediate tracheostomy in critically ill adult patients in an ICU of tertiary hospital of Andhra Pradesh. J. Evolution Med. Dent. Sci. 2016;5(84):6249-6252, DOI: 10.14260/jemds/2016/1413

\section{BACKGROUND}

Tracheostomy is required in critically ill patients to manage airway on a long term basis. ${ }^{1}$ Indications of tracheostomy have not changed, but its timing has been questioned though shown to have definite effect on the outcome of the underlying disease. ${ }^{2,3}$ Among the surgical procedures performed in critically ill patients in ICU setup tracheostomy accounts to $24 \%{ }^{4}$ This is performed when the attending physician feels that the underlying illness needs a prolonged ventilator support. 5 In spite of this situation the timing of tracheostomy has not been clearly determined, though the available data suggest an early tracheostomy gives better results.6,7

Financial or Other, Competing Interest: None.

Submission 15-09-2016, Peer Review 09-10-2016,

Acceptance 14-10-2016, Published 19-10-2016.

Corresponding Author:

Dr. Yarlagadda Subba Rayudu,

R R Speciality Hospital,

3rd Lane, Gunturuvarithota,

Guntur-522001.

E-mail:ysrayudu@gmail.com

DOI: $10.14260 /$ jemds $/ 2016 / 1413$
The advantages of tracheostomy over prolonged endotracheal intubation include improved patient comfort and reduced sedative drug use, faster weaning from mechanical ventilation, a reduced incidence of nosocomial pneumonia, and shorter hospitalisation.8,9 The incidence pneumonia is directly related to the duration of mechanical ventilation that carries significant morbidity and mortality. ${ }^{10}$ In the weight of advantages of tracheostomy performed earlier over ET intubation, a study showed in 1981 that the incidence of tracheal stenosis after tracheostomy was raised up to $65 \% .{ }^{11}$ With the recognition of causes and improved availability of tracheostomy tubes material, design, use of high-volume, low pressure cuffs, this is brought down. ${ }^{12}$ According to the recommendations of National Association of Medical Directors of Respiratory Care (NAMDR), ET intubation is to be used for patients requiring less than 10 days of mechanical respiratory support and that a tracheostomy to be done in patients still requiring ventilator support after 21 days after admission. ${ }^{13}$ These are only recommendations on expert opinion but in modern practice many broadly seem to follow them..$^{14}$ The present study contemplates to observe the role of immediate tracheostomy over the recommendations of NAMDR. 


\section{MATERIALS AND METHODS}

The present study is a prospective randomised study undertaken at NRI Medical College Hospital between Jan 2010 and Dec 2016 on 88 patients. The patients were randomised and grouped into A and B. In group A, 42 patients underwent immediate conventional tracheostomy in the ICU. In group B, 46 patients underwent elective conventional tracheostomy after a stay of 10 to 21 days in the ICU. Ethical committee clearance was taken prior to commencement of the study. Due consent was taken from the attendants of the patient prior to tracheostomy.

\section{Inclusion Criteria}

1. Patients aged above 18 years admitted to ICU with respiratory distress requiring ventilator support.

2. Patients with APACHE score equal to or more than 15.

3. Patients with head injury, traumatic brain injuries and cerebrovascular accidents and other chronic medical diseases.

\section{Exclusion Criteria}

1. Patients with previous respiratory illness as diagnosed by chest x-ray. 2. Patients with neck deformities, thyroid enlargements, obesity and tumours of the neck. 3. Patients with thyroid, oesophageal, bronchial carcinomas. 4. Patients with haematological malignancies, terminal malignancies, liver failure and renal failure. A protocol was developed in the ICU to allot the patients to two groups based on exclusion and inclusion criteria and at a random ratio of 1:1. Except to the tracheostomy care all other care and treatment was at the discretion of the treating neurosurgeons or clinicians. Immediately after the admission, the duty doctors of ICU recorded patient's demographic data, GCS score, Acute Physiology and Chronic Health Evaluation (APACHE) score, details of bedside tracheostomy. During the stay of the patient in the ICU, immediate and late complications of tracheostomy were recorded by the ENT surgeon who performed the surgery. As it was apparent from the data available in the case sheet, treatment assignment could not be blinded to the caring team. The extracted data on patients of both the groups included complete blood picture, Electrolytes, Creatinine, Coagulation profile before tracheostomy, BUN, Liver functions, and Cultures of samples from sputum, blood, and urine. Number of calendar days spent in the ICU from tracheostomy, total number of days on ventilator, time taken for weaning of tracheostomy, the number of days remained in ICU, total stay in the hospital and the final outcome of the patient were recorded and statistically analysed. ICU and hospital mortality rates were documented. Mean $\pm S D$ is given for normally distributed metric variables, frequencies and percentages are given for non-metric variables. Chi square calculator was used to know the significance of the study by calculating $p$ value ( $p$ significant at $<0.05$ ). Fisher's exact test was applied to demographic data and data of diagnosis in ICU to know the $p$ value. A p-value of $<0.05$ was considered statistically significant.

\section{OBSERVATIONS AND RESULTS}

In group $\mathrm{A}$, among the 42 patients, males were 32 and females were 10 with a male to female ratio of 3.2:1. Patients belonged to the age groups of 18 to 58 with a mean age of $43.2 \pm 2.2$. The youngest patient was aged 18 and the oldest aged 56 years
(Table 1). In group B, among the 46 patients, males were 38 and females were 8 with a male to female ratio of $5.75: 1$. Patients belonged to the age groups of 18 to 58 with a mean age of $45.2 \pm 1.2$. The youngest patient was aged 18 and the oldest was aged 58 years (Table 1 ).

\begin{tabular}{|c|c|c|c|}
\hline Groups & $\begin{array}{c}\text { Immediate } \\
\text { Tracheostomy- } \\
\text { Group A }\end{array}$ & $\begin{array}{c}\text { Elective } \\
\text { Tracheostomy- } \\
\text { Group B }\end{array}$ & $\begin{array}{c}\text { P } \\
\text { value }\end{array}$ \\
\hline Age & $43.2 \pm 13.2$ & $45.2 \pm 1.2$. & 0.06 \\
\hline Sex & $32 / 10$ & $38 / 08$ & 0.09 \\
\hline \multicolumn{3}{|c|}{ Table 1: Showing the Age and Sex Incidence } \\
of the Group A \& B patients (n=42 \& 46) \\
\hline
\end{tabular}

Even though the majority of the patients were males, there was no statistical significance between the two groups in regards with age and gender. At the time of admission in group A, the number of patients with traumatic brain injury (TBI) was 18 and with other causes of respiratory failure were 24 . In group B, the figures were 20 and 26 respectively (Table 2). However, no statistical significance was observed between the diagnosis and timing of the tracheostomy.

\begin{tabular}{|c|c|c|c|c|c|}
\hline \multirow[t]{2}{*}{$\begin{array}{l}\text { Diagnosis } \\
\text { in ICU }\end{array}$} & \multicolumn{2}{|c|}{$\begin{array}{c}\text { Early } \\
\text { Tracheostomy }\end{array}$} & \multicolumn{2}{|c|}{$\begin{array}{c}\text { Elective } \\
\text { Tracheostomy }\end{array}$} & \multirow{2}{*}{$\begin{array}{c}\text { Test } \\
\text { Significance } \\
\text { Easy Fisher } \\
\text { Exact Test } \\
\text { Calculator- } \\
\mathrm{P}=<0.05\end{array}$} \\
\hline & $\mathbf{N}$ & $\%$ & $\mathbf{N}$ & $\%$ & \\
\hline $\begin{array}{c}\text { Traumatic Brain } \\
\text { Injury (CI, SAH, } \\
\text { SDH, EDH) }\end{array}$ & 18 & 42.85 & 20 & 43.47 & 1 \\
\hline $\begin{array}{c}\text { Cerebrovascular } \\
\text { Accident CVA }\end{array}$ & 09 & 21.42 & 09 & 19.56 & 1 \\
\hline $\begin{array}{c}\text { Renal Failure } \\
\text { (Acute+ Chronic) }\end{array}$ & 10 & 23.80 & 09 & 19.56 & 0.49 \\
\hline $\begin{array}{c}\text { Respiratory } \\
\text { Failure } \\
\text { (Type II, COAD) }\end{array}$ & 05 & 11.90 & 08 & 17.39 & 0.49 \\
\hline Tetanus & 00 & 00 & 00 & 00 & 00 \\
\hline$T a b$ & $3 r$ & $n g t$ & Dia. & $\begin{array}{l}\text { Sis } n \\
2 \& 4\end{array}$ & \\
\hline
\end{tabular}

(CI: Concussion Injury, SAH: Subarachnoid Haemorrhage, SDH: Subdural Haemorrhage, EDH: Extradural Haemorrhage, CVA: Cerebrovascular Accident, COAD: Chronic Obstructive Airway Disease).

In group A, the APACHE score was $20.82 \pm 1.5$ and in group $B$ it was $22.38 \pm 2.1(p=1)$. In group $B$, the GCS score was $5.2 \pm 1.86$ and in group $B$ it was $5.8 \pm 2.3$. There was no statistically significant difference between both groups regarding the mean GCS $(p=1)$. There was no significant statistical difference in the laboratory data collected like CBC, PT, INR, chemistry, blood, in both groups. But the APTT was higher in group B when compared to group A (37.13 $\pm 4.41 \mathrm{Vs}$. 28.27 \pm 3.46 ; $p=0.020$ ), but both readings were within normal limits. Tracheostomy related intraoperative and postoperative complications showed no difference among the two groups and were also not statistically significant. But the percentage of complications observed post-operatively in group B was more than in group A (Table 3). Though the incidence of pneumonia in group B was more in percentage, the values were not significant on calculation with chi square 
test calculator giving a p value of 0.804 ( $p$ significant at $<0.05$ ), (Table 4). Patients of both the groups showed no difference in the mortality outcome and were not statistically significant (Table 5). Group A patients required a significantly shorter duration of ventilator support when compared to group B patients (Group A $11.20 \pm 1.58$ Vs. group B 23.23 \pm 2.66 ; p= 0.020 ), shorter ICU stay (group A $13.60 \pm 1.0$ Vs. group B $28.50 \pm 2.60 ; 0.020$ ), shorter hospital stay (Group A 16.12 \pm 2.20 Vs. group B 35.40 $\pm 1.60 ; p=0.020$ ).

\begin{tabular}{|c|c|c|c|c|}
\hline Complications & \multicolumn{2}{|c|}{$\begin{array}{c}\text { Early } \\
\text { Tracheostomy- } \\
\mathbf{4 2}\end{array}$} & \multicolumn{2}{c|}{$\begin{array}{c}\text { Elective } \\
\text { Tracheostomy- } \\
\mathbf{4 6}\end{array}$} \\
\hline & $\mathrm{N}$ & $\%$ & $\mathrm{~N}$ & $\%$ \\
\hline Pneumothorax & 01 & 2.38 & 03 & 6.52 \\
\hline Sepsis & 03 & 7.14 & 02 & 4.34 \\
\hline $\begin{array}{l}\text { Ventilation } \\
\text { Associated } \\
\text { Pneumonia }\end{array}$ & 05 & 11.90 & 20 & 43.47 \\
\hline $\begin{array}{c}\text { Table 3. Showing Intraoperative and Postoperative } \\
\text { Complications of both the Groups, (n=42 \& 46) }\end{array}$ \\
\hline
\end{tabular}

\begin{tabular}{|c|c|c|c|c|}
\hline \multirow{2}{*}{$\begin{array}{c}\text { Timing of } \\
\text { Tracheostomy }\end{array}$} & $\begin{array}{c}\text { Immediate } \\
\text { Tracheostomy- } \\
\text { Group A (5) }\end{array}$ & \multicolumn{2}{c|}{$\begin{array}{c}\text { Elective } \\
\text { Tracheostomy- } \\
\text { Group B (20) }\end{array}$} \\
\cline { 2 - 5 } & $\mathbf{N}$ & $\mathbf{\%}$ & $\mathrm{N}$ & \% \\
\hline 0-4 Days & 0 & & 03 & 6.52 \\
\hline 5-10 Days & 01 & 2.38 & 03 & 6.52 \\
\hline 11-15 Days & 01 & 2.38 & 04 & 8.69 \\
\hline 16-20 Days & 02 & 4.76 & 04 & 8.69 \\
\hline > 21 Days & 01 & 2.38 & 06 & 13.04 \\
\hline Table 4. Showing the Incidence of Pneumonia in \\
both the Groups (n=42 \& 46). P Value 0.804 \\
\hline
\end{tabular}

\begin{tabular}{|c|c|c|c|c|}
\hline \multirow{2}{*}{ Mortality } & \multicolumn{2}{|c|}{$\begin{array}{c}\text { Early } \\
\text { Tracheostomy }\end{array}$} & \multicolumn{2}{c|}{$\begin{array}{c}\text { Elective } \\
\text { Tracheostomy }\end{array}$} \\
\hline & $\mathrm{N}$ & $\mathbf{\%}$ & $\mathrm{N}$ & $\%$ \\
\hline Expired & 5 & 11.90 & 5 & 10.86 \\
\hline \multicolumn{2}{|c|}{ Table 5: Showing the Mortality Rate } \\
in both Groups, (n=42 \& 46) \\
\hline
\end{tabular}

\section{DISCUSSION}

Review of literature shows many randomised studies observing reduction in ventilator support, incidence of pneumonia and reduced mortality among the patients undergoing early tracheostomy when compared to late tracheostomy. ${ }^{15,16}$ There is considerable variation in timing the tracheostomy when various centres are compared.17,18 Even the recommendations of NAMDR do not specify the timing but leaves a margin of 11 days between $10^{\text {th }}$ and $21^{\text {st }}$ day to decide the timing of tracheostomy when a prolonged ventilator support is required. In such a scenario, the main aim of this study is to observe the advantages of immediate tracheostomy over elective tracheostomy in terms of duration of ventilator support, ICU stay, hospital stay, incidence of pneumonia (VAP) and hospital outcome. In the present study, the demographic data like age, sex, clinical diagnosis on admission (APACHE II score, GCS score), underlying diseases and comorbidities were almost similar between both the groups. There was no statistical significance also.
Head Injuries resulting in traumatic brain Injury and followed by cerebrovascular accident (CVA) were the commonest causes of ICU admissions that required tracheostomy. This may be due to alarmingly increasing road traffic accidents. Milo Engoren 200419 in his retrospective chart review with prospective evaluation of functional status noted similar increase in TBI patients. Also in a prospective study by Raees Ahmed et al (2010), in medical-surgical ICU in Emirates out of 117 tracheostomies, around $50 \%$ of the patients were of road traffic accidents resulting in traumatic brain injury. The total percentage of intraoperative and postoperative complications in both the groups in the present study was $73.4 \%$ during their ICU stay. The incidence of pneumonia in both the groups was $60.37 \%$. The other complications included pneumothorax, sepsis, accounted for $20.25 \%$.

The percentage of complications was observed to be more in elective tracheostomy. However, this was not statistically significant. Observing the total incidence pneumonia in both groups was more in elective tracheostomy group than immediate group. In similar studies by Wise (2002), Fikkers (2004), and Yw Li (2009) the incidence of pneumonia was more in late tracheostomies. ${ }^{20-22}$ Studies in support of early tracheostomy especially in medical ICU patients was noted by Rumbark ${ }^{23}$ et al (2004) where physicians require a prolonged ventilator support at high risk of pneumonia, sepsis and death. The outcome of the present study mainly focuses upon the significantly shorter duration of ventilator support in immediate tracheostomy group versus elective group, $(11.20 \pm 9.8$ Vs. $23.40 \pm 8.4 ; \mathrm{p}=0.04)$. This observation is similarly found in the study of Gatti et al Zagli et al.24,25 But opposed by Terragni ${ }^{26}$ et al, though these studies are conducted between early and late tracheostomies they are also significant in the present study. The present study also emphasises on the results showing shorter ICU stay (Group A $13.60 \pm$ Vs. group B 28.50 $\pm 6.60 ; p=0.045$ ) and shorter total hospital stay (group A 16.12 \pm 3.20 Vs. group B 35.40 \pm 1.60 ; $p=$ 0.040 ) and final hospital outcome, which were shorter in the immediate tracheostomy group when compared to elective tracheostomy group. This is confirmed by the results of Lee ${ }^{27}$ (2005). The present study is also in conformity with a similar study by Zheng et al (2012) who found that early tracheostomy resulted in more ventilator free, sedation free, and in the patient's ICU free days, higher successful weaning, and ICU discharge rate, and lower ICU incidence of VAP. There were no statistically significant values among the mortality cases in the present study when both the groups are compared. But we state that there was no mortality attributed to the immediate tracheostomy and complications due to immediate tracheostomy.

\section{Limitations of the Present Study}

The present study population was small because of securing immediate consent for immediate tracheostomy had to be inculcated in the ICU staff as it was not practised in these parts of Andhra Pradesh. Further studies are required in this angle for the study to be more conclusive. The study was not blinded so there was a chance for performance bias which could have influenced the results. The decision of final weaning of tracheostomy was left with the ENT surgeon rather than the attending physician. 


\section{CONCLUSIONS}

The role of immediate tracheostomy in critically ill patients though not convincing in changing the final outcome of the of the hospitalisation and mortality but is influential in reducing the secondary outcomes like duration of ventilator support, length of ICU stay and total hospital stay. These results are statistically significant with a p value at $0.041(\mathrm{p}<0.05$ being significant).

\section{REFERENCES}

1. Kahveci SF, Goren S, Kutlay O, et al. Bedside percutaneous tracheostomy experience with 72 critically ill patient. Eur J Anaesthesiol 2000;17(11):688-91.

2. Nates JL, Cooper DJ, Myels PS, et al. Percutaneous tracheostomy in critically ill patients: a prospective, randomized comparison of tow techniques. Crit Care Med 2000;28(11):3734-9.

3. Denis BM, Eckert MJ, May AK, et al. Safety bedside percutaneous tracheostomy in critically ill: evaluation of more than 3000 procedures. J Am Coll Surg 2013;216(4):858-65.

4. Fischler L, Erhart S, Kleger GR, et al. Prevalence of tracheostomy in ICU patients. A nation-wide survey in Switzerland. Intensive Care Med 2000;26(10):1428-33.

5. De Leyn P, Bedert L, Delcroix M, et al. Tracheotomy: clinical review and guidelines. Eur J Cardiothorac Surg 2007;32(3):412-21.

6. Zlung Y, Sui F, Chen XK, et al. Early versus late percutaneous tracheostomy in critically ill patients anticipated requiring prolonged mechanical ventilation. Chin Med J (Engl) 2012;125(11):1925-30.

7. Pinheiro Bdo V, Tostes Rde O, Brum CI, et al. Early versus late tracheostomy in patients with acute severe brain injury. J Bras Pneumol 2010;36(1):84-91.

8. Plummer AL, Gracey DR. Consensus conference on artificial airways in patients receiving mechanical ventilation. Chest 1989;96(1):178-80.

9. Vincent JL, Lobo S, Struelens M. Ventilator associated pneumonia: risk factors and preventive measures. J Chemother 2001;1(1):211-7.

10. Rello J, Ollendorf DA, Oster G, et al. Epidemiology and outcomes of ventilator-associated pneumonia in a large US database. Chest 2002;122(6):2115-21.

11. Stauffer JL, Olson DE, Petty TL. Complications and consequences of endotracheal intubation and tracheotomy. A prospective study of 150 critically ill adult patients. Am J Med 1981;70(1):65-76.

12. Wain JC. Postintubation tracheal stenosis. Chest Surg Clin N Am 2003;13(2):231-46.

13. Durbin CG. Indications for and timing of tracheostomy. Respir Care 2005;50(4):483-7.
14. Glossop AJ, Meekings TC, Hutchinson SP, et al. Complications following tracheostomy insertion in critically ill patients-experience from a large teaching hospital. JICS 2011;12(4):301-6.

15. Ciaglia P, Fersching R, Syniec C. Elective percutaneous dilatational tracheostomy: a new simple bedside procedure preliminary report. Chest 1985;87(6):715-9.

16. Knaus WA, Draper EA, Wagner DP, et al. APACHE II: a severity of disease classification system. Crit Care Med 1985;13(10):818-29.

17. Krishnan K, Elliot SC, Mallick A. The current practice of tracheostomy in the United Kingdom: a postal survey. Anaesthesia 2005;60(4):360-4.

18. Salcedo 0, Frutos-Vivar F. Tracheostomy in ventilated patients. What do we do it for? Med Intensiva 2008;32(2):91-3.

19. Engoren M, Arslanion-Engoren C, Frnn- Budrer N. Hospital and long-term outcome after tracheostomy for respiratory failure. Chest 2004;125(1):220-7.

20. Wise H. Experience of complications of percutaneous dilatational tracheostomy. Anaesthesia 2002;57(2): 195-7.

21. Fikkers BG, Van Veen JA, Kooloos JG, et al. Emphysema and pneumothorax after percutaneous tracheostomy: case reports and anatomic study. Chest 2004;125(5): 1805-14.

22. Li YW, Chandan GS. Bilateral tension pneumothorax following percutaneous tracheostomy. JICS 2009;10(4):295-6.

23. Rumbak MJ, Newton M, Truncale $\mathrm{T}$, et al. A prospective, randomized study comparing early percutaneous dilatational tracheostomy to prolonged translaryngeal intubation in critically ill medical patients. Crit Care Med 2004;32(8):1689-94.

24. Gatti G, Cardu G, Bentini C, et al. Weaning from ventilator after cardiac operation using the ciaglia percutaneous tracheostomy. Eur J Cardiothorac Surg 2004;25(4):541-7.

25. Zagli G, Linden M, Spina R, et al. Early tracheostomy in ICU: a retrospective study of 506 cases of video-guided ciaglia blue rhino tracheostomies. J Trauma 2010;68(2): 367-72.

26. Terragni PP, Antonelli M, Fumagalli R, et al. Early vs late tracheotomy for prevention of pneumonia in mechanically ventilated adult ICU patients: a randomized controlled trial. JAMA 2010;303(15):1483-9.

27. Lee JC, Fink MP. Early percutaneous dilatational tracheostomy leads to improved outcomes in critically ill medical patients as compared to delayed tracheostomy. Crit Care 2005;9(4):E12. 